WellBeing International

WBI Studies Repository

12-1999

\title{
A Preliminary Investigation of the Construct of Psychopathic Personality (Psychopathy) in Chimpanzees (Pan troglodytes)
}

\author{
Scott O. Lilienfeld \\ Emory University \\ Jonathan Gershon \\ Emory University \\ Marshall Duke \\ Emory University \\ Lori Marino \\ Emory University \\ Frans B. M. de Waal \\ Emory University
}

Follow this and additional works at: https://www.wellbeingintlstudiesrepository.org/acwp_asie

Part of the Animal Studies Commons, Comparative Psychology Commons, and the Other Animal Sciences Commons

\section{Recommended Citation}

Lilienfeld, S. O., Gershon, J., Duke, M., Marino, L., \& de Waal, F. (1999). A preliminary investigation of the construct of psychopathic personality (psychopathy) in chimpanzees (Pan troglodytes). Journal of comparative psychology, 113(4), 365.

This material is brought to you for free and open access by WellBeing International. It has been accepted for inclusion by an authorized administrator of the WBI Studies Repository. For more information, please contact wbisr-info@wellbeingintl.org.

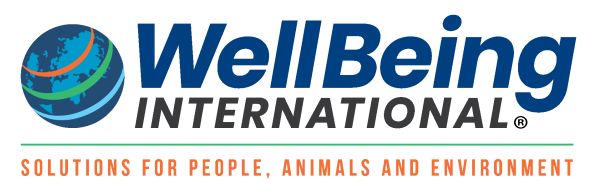




\title{
A Preliminary Investigation of the Construct of Psychopathic Personality (Psychopathy) in Chimpanzees (Pan troglodytes)
}

\author{
Scott O. Lilienfeld, Jonathan Gershon, Marshall Duke, Lori Marino, and Frans B. M. de Waal \\ Emory University
}

\begin{abstract}
Although the construct of psychopathy has received considerable attention in humans, its relevance to other animals is largely unknown. We developed a measure of psychopathy for use in chimpanzees (Pan troglodytes), the Chimpanzee Psychopathy Measure (CPM), and asked 6 raters to complete this index on 34 chimpanzees. The CPM (a) demonstrated satisfactory interrater reliability and internal consistency; (b) exhibited marginally significant sex differences (males > females); (c) correlated positively with measures of extraversion, agreeableness, and observational ratings of agonism, sexual activity, daring behaviors, teasing, silent bluff displays, and temper tantrums, and negatively with observational ratings of generosity; and (d) demonstrated incremental validity above and beyond a measure of dominance. Although further validation of the CPM is needed, these findings suggest that the psychopathy construct may be relevant to chimpanzees.
\end{abstract}

Although the construct of psychopathic personality (psychopathy) has received considerable attention in the literature pertaining to humans (Lykken, 1995), its applicability to other animals is largely unknown. As first systematically delineated by Cleckley ( 194111982), psychopathy is conceptualized as a constellation of such personality traits as guiltlessness, lack of empathy, dishonesty, self-centeredness, failure to form intimate attachments with others, poor impulse control, failure to learn from punishment, aggressiveness, risk taking, and superficial charm (see also Hare, 1991; Lykken, 1957; McCord \& McCord, 1964). Cleckley emphasized that psychopaths are free of anxiety symptoms and bizarre behaviors and often impress others as well adjusted. Men have consistently been found to have higher levels of psychopathic traits than women (Lilienfeld, 1992; Widom, 1984).

It is unclear whether psychopathy is best regarded as a taxon (i.e., nonarbitrary class that exists in nature) or dimension (Meehl \& Golden, 1982). If psychopathy is taxonic, this might render research on this condition in unselected samples problematic because these samples may be characterized by low base rates of the psychopathy taxon (Lilienfeld, 1994). Harris, Rice, and Quinsey (1994) applied taxometric analyses (Meehl \& Golden, 1982) to the scores of prisoners on the Psychopathy Checklist (Hare, 1991), which is the most extensively validated measure of psychopathy. Harris et al. found that the antisocial behaviors (e.g., stealing in childhood) sometimes associated with psychopathy were underpinned by a latent taxon, whereas the core personality features of psychopathy (e.g., lack of guilt) were underpinned by a latent dimension.

Although researchers have examined personality variables in a variety of mammals (see Gosling \& John, 1999), including rats (Garcia-Sevilla, 1984), dogs (Draper, 1995), hyenas (Gosling, 1998b), baboons (Sapolsky, 1990), and rhesus (Chamove, Eysenck, \& Harlow, 1972; Stevenson Hinde \& Zunz, 1978; 
Suomi, 1991) and stumptail (Figueredo, Cox, \& Rhine, 1995) macaques, few investigators have examined across- or within-species differences in psychopathic personality traits. Solomon (1960) examined dog breed differences in the capacity to resist a tempting food treat that resulted in punishment. He noted that in contrast to certain breeds (e.g., Shetland sheepdogs), which quickly learned to avoid temptations, "Basenjis seem to be constitutional psychopaths and it is very difficult to maintain taboos in such dogs" (p. 402). Lykken (1995) discussed the bull terrier as an animal model of the predisposition to psychopathy and argued that this dog breed is fearless and "relatively indifferent to punishment" (p. 13).

To our knowledge, however, the construct of psychopathy has not been examined explicitly in great apes. Nevertheless, the ethological literature on chimpanzee behavior provides several intriguing suggestions regarding individual differences relevant to psychopathy. For example, de Waal (1998) described one female chimpanzee in his Arnhem colony, named Puist, as "two-faced and mean ... deceitful or mendacious." He observed, "She ... may invite her opponent to reconciliation in the customary way. She holds out her hand and when the other hesitantly puts her hands in Puist's, she suddenly grabs hold of her" (de Waal, 1998, p. 55). Goodall (1990) described the behaviors of a chimpanzee mother-daughter team, Passion and Porn, who over a 4-year period brutally cannibalized at least 8 infants. Goodall (1990) referred to Passion as a "cold mother" (p. 33) and noted that neither Passion nor Porn formed strong attachments to group members. Moreover, both chimpanzees were fearless in the company of adult baboons, from whom most other chimpanzees kept a respectful distance. Using a standardized observational measure known as the Emotions Profile Index, Buirski and Plutchik (1991) found that Passion exhibited markedly higher levels of aggression and distrust and markedly lower levels of timidity and control compared with norms derived from 10 other female chimpanzees. In sum, Puist, Passion, and Porn appeared to display several traits consistent with psychopathy, including deceptiveness, callousness, aggressiveness, absence of emotional ties, and fearlessness.

In addition, several investigators have recently examined the structure of personality traits in several great ape species, including chimpanzees (King \& Figueredo, 1997) and gorillas (Gold \& Maple, 1994). One influential taxonomy of human personality is the Five Factor Model (FFM), which comprises the "Big Five" traits of extraversion, neuroticism, conscientiousness, agreeableness, and openness to experience (Costa \& McCrae, 1992). Because several Big Five traits, including (reversed) conscientiousness, (reversed) agreeableness, and perhaps extraversion, are associated with psychopathy in humans (Harpur, Hart, \& Hare, 1994; Hart \& Hare, 1994), an examination of these traits may prove relevant to the construct of psychopathy in nonhuman primates.

King and Figueredo (1997) asked zoo employees and volunteers to provide personality ratings on 100 chimpanzees at 12 zoological parks. Factor analyses of these ratings revealed a six-factor structure, which in turn revealed a set of traits similar to the Big Five and an additional trait of dominance. King and Figueredo's findings suggest that the structure of personality in chimpanzees may overlap substantially with that of humans and that chimpanzees exhibit individual differences in personality traits (e.g., agreeableness) associated with psychopathy in humans. Although King and Figueredo's ratings exhibited high levels of interrater reliability, it could nevertheless be argued that this consensus was attributable to raters' reliance on obvious but invalid external cues, such as physical appearance (Kenrick \& Funder, 1988). Significant correlations between these ratings and observational data on behavior would help to exclude this hypothesis.

The construct of psychopathy may be relevant to chimpanzees for several reasons. First, the temperamental dimension that has proven most useful for understanding individual differences in nonhuman primates is a fearless-fearful or bold-shy continuum (Clarke \& Boinski, 1995). Some authors (e.g., Lykken, 1995) have argued that fearlessness is the core trait underlying psychopathy and that early appearing individual differences in behavioral inhibition to unfamiliar stimuli (Kagan, Reznick, \& Snidman, 
1987) may give rise to individual differences in the features of psychopathy. Second, an increasing body of evidence suggests that chimpanzees are capable of manipulation and deception (de Waal, 1992, 1998; Menzel, 1974; Savage-Rumbaugh \& McDonald, 1988; Woodruff \& Premack, 1979), although the extent to which chimpanzees understand that they can deceive others is controversial (Hauser, 1997). On the basis of observations of power struggles among male chimpanzees at the Arnhem Zoo, de Waal (1998) drew comparisons with Machiavelli and coined the term chimpanzee politics. This concept was extended to ideas regarding "Machiavellian intelligence" by Byrne and Whiten (1988) and was corroborated for social maneuvering and scheming in wild chimpanzees by Nishida and Hosaka (1996). Third, some authors contend that chimpanzees possess the rudiments of morality, including empathy, prescriptive social roles, aggression against rule violators ("moralistic aggression"), and reconciliation (e.g., de Waal, 1991, 1998). If so, chimpanzees might exhibit individual differences in these capacities, some of which may be associated with traits characteristic of psychopathy (e.g., lack of guilt) in humans. Fourth, chimpanzees are virtually unique among great apes in their levels of intra- and intergroup aggression (Goodall, 1991; Wrangham \& Peterson, 1996), both of which may be etiologically related to the aggression often observed in human psychopaths. Moreover, as in humans, male chimpanzees are much more aggressive than females (Wrangham \& Peterson, 1996).

In this study, we examined the construct of psychopathy in chimpanzees with a "top-down" approach (see Gosling, 1998a; Zuckerman, 1984), whereby a construct that is well understood in humans is examined in other animals to elucidate its relevance to other species. Because shared characteristics in two closely related groups often derive from common evolutionary ancestry, one might expect some continuity in the mental capacities of humans and chimpanzees. We therefore constructed a measure of psychopathy in chimpanzees consisting of personality trait referents analogous to traits described in human psychopaths (e.g., Cleckley, 194111982) and examined this measure's personality and behavioral correlates. In developing this measure, we began with the assumption that the core personality traits of psychopathy are underpinned by a latent dimension, rather than a taxon (Harris et al., 1994; but see Mealey, 1995, for a contrasting view), and that this dimension can be meaningfully applied to all chimpanzees. ${ }^{1}$ To address the possibility that our findings were attributable to raters' reliance on obvious but erroneous external cues, we collected observational data on a variety of behaviors, a subset of which was deemed relevant to psychopathy.

We predicted that our measure of psychopathy in chimpanzees would be reliable across raters and internally consistent. High internal consistency would support the contention that psychopathy is a syndrome, which in almost all cases can be defined as a constellation of co-varying indicators (Kazdin, 1983). In addition, we predicted that this measure would be associated with (a) personality traits characteristic of psychopathy in humans, such as (reversed) agreeableness, and (b) observational measures of aggressiveness, physical risk taking, greediness, sexual activity, and (reversed) generosity. Moreover, using partial correlations, we examined the extent to which our measure of psychopathy possessed incremental validity (Sechrest, 1963) above and beyond an index of dominance in the prediction of behavioral observations (see also Gosling, 1998b). These analyses were motivated by findings suggesting that dominance (a) may be of particular importance in chimpanzee personality (Gosling \& John, 1999; King \& Figueredo, 1997) and (b) is strongly and positively associated with psychopathy in humans (Harpur, Hare, \& Hakstian, 1989).

\section{Method}

\section{Subjects and Housing}

Subjects were 34 common chimpanzees (Pan troglodytes) housed at the Yerkes Regional Primate Research Center Field Station in Lawrenceville, Georgia. These chimpanzees are separated into two 
large outdoor compounds connected to indoor quarters. The compound for Group 1 is approximately 750 $\mathrm{m}^{2}$, whereas the compound for Group 2 is approximately $630 \mathrm{~m}^{2}$. Both compounds contain numerous play objects and structures, including ladders, tires, and plastic barrels. Observation towers are situated above each compound. Visibility from these towers is unobstructed except when animals are along the walls immediately adjacent to the tower.

Group 1 consists of 16 chimpanzees (12 females) that range in age from 1 to 33 years. This group contains 2 adult (i.e., age of 9 or above) males, 8 adult females, 2 adolescent (i.e., age between 3 and 9 ) males, 3 adolescent females, and 1 juvenile (i.e., age less than 3) female. Group 2 consists of 18 chimpanzees (11 females) that range in age from 2 to 31 years. This group contains 2 adult males, 6 adult females, 5 adolescent males, 3 adolescent females, and 2 juvenile females.

\section{Procedure}

Construction of the psychopathy measure. The Chimpanzee Psychopathy Measure (CPM) was constructed as part of a larger study designed to examine the relations between a broad spectrum of personality traits and behavior among chimpanzees (Gershon, 1998). The initial version of the CPM consisted of a set of personality adjectives adapted from personality inventories used with other primate species, including rhesus monkeys and gorillas (Bolig, Price, O'Neill, \& Suomi, 1992; Caine, Earle, \& Reite, 1983; Gold \& Maple, 1994; Stevenson-Hinde, Stillwell-Barnes, \& Zunz, 1980; Stevenson-Hinde \& Zunz, 1978). Each CPM item consists of an adjectival trait (e.g., "confident") followed by a brief description of chimpanzee behaviors relevant to this trait (e.g., "behaves in a positive, assured manner, not restrained or tentative"). Rather than focusing on specific behaviors (e.g., "often bites other chimpanzees"), which tend to exhibit low consistency across situations and to possess a high degree of "situational uniqueness" (Epstein, 1979), we elected to focus on broader composites of functionally equivalent behaviors (e.g., "aggressive"). Although this focus on broader behavioral composites necessitates a greater degree of rater inference, it permits raters to mentally aggregate across multiple instances of behavior within a single category. Such aggregration can typically be expected to cancel out random situational error or "noise" and produce enhanced reliability and validity (Epstein, 1979).

Although a number of items on the preliminary version of the measure appeared relevant to psychopathy, the questionnaire was supplemented with several items more directly relevant to psychopathy (e.g., "boredom prone," "fails to learn from punishment"). These items were modeled after traits commonly described in the human psychopathy literature, particularly the clinical writings of Cleckley (194l/1982), McCord and McCord (1964), and Hare (1991). The final version of the CPM, which consists of 23 items (10 of which are reversed in scoring), can be seen in Table 1. Each CPM item was rated on a scale from 1 to 5, where 1 indicated that the personality trait in question is weakly represented, or is not present at all and 5 indicated that this trait is very strong and conspicuous, approaching the extreme. When rating chimpanzees on each item, raters were asked to judge how each chimpanzee compared with other chimpanzees of the same age and sex. These instructions, which were modeled after those used in some observer rating questionnaires in the human literature (e.g., Harkness, Tellegen, \& Waller, 1995), were provided to minimize the possibility that the personality ratings would be confounded by age and sex.

The 23 CPM items, along with 14 additional items intended to assess other personality variables (see the following paragraph), were interspersed into a questionnaire totaling 37 items. This questionnaire was distributed to six raters who were familiar with the chimpanzees and had observed them for periods of months or years. One of the six raters, however, stated that he did not know the infant chimpanzees sufficiently well to complete ratings of these animals, so he only rated the 27 chimpanzees who were 5 years of age and above. In addition, one of the raters stated that he did not know the chimpanzees in 
Group 2 sufficiently well to complete ratings of these animals, so he only rated the animals in Group 1 . As a consequence, the mean number of raters per animal was 5.2, rather than 6 .

Assessment of other personality traits. The items on the CPM, along with the 14 additional personality items, were mailed to seven researchers with particular expertise in the FFM. These researchers were asked to classify each trait into one of the Big Five dimensions. They were told that if a trait appeared to assess more than one Big Five dimension, they should select the Big Five dimension that provided the best match to this trait. Items were classified into a Big Five dimension if at least five of the seven researchers agreed on the placement of the item.

Table 1. CPM Items and Corrected Item-Total Correlations

\section{Type of behavior}

Aggressive: causes harm or potential harm, displays, chases, bites, etc.

Apprehensive $(\mathrm{R})$ : seems to be anxious about everything; fears and avoids any kind of risk

Boredom-prone: needs to stir up excitement when nothing is happening

Confident: behaves in a positive, assured manner, not restrained or tentative

Deceptive: tends to be "sneaky" and to cheat or manipulate others

Delays gratification $(R)$ : is good at waiting his/her tum for food or other pleasurable activities

Dominant: elicits submissive behavior from others

Eccentric (R): shows stereotyped or unusual mannerisms; coprophagy, regurgitation, rocking, pacing, selfclasping, etc.

Fails to learn from punishment: makes the same mistakes over and over again

Fearful (R): displays fear grins; retreats readily from others or outside disturbances

Generous (R): willingly shares food or other desired objects

Greedy: takes more than his/her share of food or other rewards

Impulsive: tends to engage in activities before considering their likely consequences

Insecure (R): hesitates to act alone; seeks reassurance from others

Irritable: reacts negatively with little provocation

Loyal $(R)$ : enters into strong and stable relationships and coalitions with others

Opportunistic: seizes a chance as soon as it arises

Popular: is sought out as a companion by others

Risk taking: is something of a "daredevil"; readily challenges others or engages in dangerous activities

Short tempered: has a "short fuse"; quickly responds with outbursts of anger and aggression to minor frustrations

Sympathetic $(R)$ : experiences distress in response to others' distress

Tense $(\mathrm{R})$ : shows restraint in posture and movement; carries the body stiffly, which suggests a shrinking tendency, as if trying to pull back and be less conspicuous

Understanding $(\mathrm{R})$ : demonstrates knowledge of others' intentions by responding in an appropriate manner to the behavior of others

Note. Corrected item-total $r=$ the correlation between each CPM item and the total CPM score with that item removed. $N=34$. Items followed by $(\mathrm{R})$ are reversed in scoring. $\mathrm{CPM}=$ Chimpanzee Psychopathy Measure.

There was a sufficient number of agreements among the seven researchers to generate adequate

measures for three of the Big Five dimensions: Agreeableness (9 items), Extraversion (11 items), and item-total $r$

Corrected 
Neuroticism (7 items). The other two Big Five factors, Conscientiousness and Openness to Experience, received agreements on only two items and one item, respectively, and were therefore not used in the analyses reported here. ${ }^{2}$ The mean number of agreements per item (out of a maximum of 7 agreements) for each of the Big Five dimensions were 5.9 (Agreeableness), 5.5 (Extraversion), 5.5 (Neuroticism), 5.3 (Conscientiousness) and 4.3 (Openness to Experience).

Because a number of CPM items were present on the Agreeableness, Extraversion, and Neuroticism scales, non-overlapping versions of these three scales were used in the correlational analyses reported here. The non-overlapping versions of the Agreeableness, Extraversion, and Neuroticism scales consisted of two (nurturant and protective), six (active, slow [reversed], sociable, solitary [reversed], subordinate [reversed], and playful), and two items (equable [reversed] and excitable), respectively. Scores on these three scales were obtained by summing the scores across all raters. The internal consistencies of the non-overlapping Agreeableness, Extraversion, and Neuroticism scales, as measured by Cronbach's alpha, were $.83, .88$, and .77 , respectively.

\section{Observational data}

Observational data were collected by two trained observers (Jonathan Gershon and a research assistant), who conducted focal observations (Altmann, 1974) on each animal using a behavioral ethogram. Both observers had previously completed CPM ratings on each animal. The focal sessions lasted for 15 min each, with 12 sessions conducted on each animal (6 in the morning and 6 in the afternoon), and were completed over a period of 12 weeks. Using a prearranged schedule, the observers watched each animal an equivalent length of time during morning and afternoon sessions, and all animals were observed for the same total length of time. Observers recorded ethogram data using binoculars, tape recorders, and timers. Observers stayed at opposite ends of the observation tower during focal sessions to minimize the possibility that they would influence each other's ratings.

The coding procedure used in this study was based on an ethogram developed by van Hooff (1973) and research by de Waal and Hoekstra (1980) and de Waal and van Hooff (1981). The primary ethogram we used consisted of a list of readily observable behaviors, a number of which (e.g., agonism, greediness, bluff displays) were a priori deemed relevant to psychopathy. In addition to these behaviors, a set of variables referred to as complex variables were coded. These variables (e.g., rejection, generosity) are more subjective and inferential than other ethogram behaviors and typically subsume multiple behaviors. For each set of ethogram variables, both performing and receiving behaviors were coded. (A complete listing of each ethogram item, along with a brief description of items whose behavioral referents are not self-evident, can be found in the Appendix.)

The interrater reliability of the primary ethogram observations, which was indexed by the kappa statistic, was assessed by having both observers record focal data for 10 sessions concurrently. Eighty-two percent of all incidents were recorded by both observers. For these cases, the interrater reliability across all ethogram items was .99. The $18 \%$ of incidents not recorded by both raters was attributable to obstructed views along the walls adjacent to the observation towers and the need to stand at opposite ends of the observation tower during coding sessions.

The final portion of the ethogram consisted of ad libitum data, which comprise behaviors that occur relatively infrequently (e.g., high-intensity agonism, mounting, and teasing). Chimpanzees were not fed during ad libitum sessions; if feeding had taken place, behavioral observations were not made until at least $15 \mathrm{~min}$ had passed. Several of the ad libitum behaviors overlapped with those coded in the primary ethogram and were coded in the ad libitum data as well because they were expected to be rare. To ensure that these behaviors were not ignored during focal sessions, the observers repeatedly checked for 
them within the entire group. To determine the frequencies of ad libitum behaviors, observers recorded the amount of time spent on the observation tower during each session. Again, both performing and receiving behaviors were coded.

Analyses

The principal analyses of interest consisted of zero-order correlations between the CPM and measures of personality dimensions and observational data derived from ethogram ratings. Performing and receiving ethogram behaviors that occurred in fewer than $5 \%$ (i.e., 2) of the animals were excluded from the analyses. Because of the low sample size $(N=34)$ and resultant low statistical power of the analyses, marginally significant findings (i.e., . $05<p<.10$ ) were designated as statistically non-significant trends. In addition, we computed partial correlations between the CPM and ethogram ratings after controlling for dominance to ascertain the incremental validity of the CPM above and beyond dominance.

\section{Results}

Interrater Reliability

The intra-class correlation (ICC) for the CPM for individual raters, ICC $(3,1)$, was .61. An analysis of the interrater reliability of mean ratings (based on a mean of 5.2 raters per chimpanzee) yielded an intra-class correlation, ICC $(k, 1)$, of .89 (where $k=$ the mean number of raters per chimpanzee). These interrater reliabilities compare favorably with those reported in the literature on chimpanzee personality (e.g., King \& Figueredo, 1997, p. 265) as well as with those reported in the human personality literature (Kenrick \& Funder, 1988). Because of these high interrater reliabilities, the CPM scores of all raters were combined into a mean CPM score, which was used in all subsequent analyses.

\section{Internal Consistency}

The internal consistency of the CPM, as measured by Cronbach's alpha, was high (.91). To provide a more fine-grained analysis of internal consistency, we examined corrected item-total correlations (i.e., the correlations of each item with the total CPM score minus that item) for each CPM item (see Table 1). All 23 item-total correlations were positive. With the exception of "popular," whose item-total correlation was negligible, all item-total correlations exceeded .20, and 17 of the 23 items had item-total correlations of .50 or greater.

\section{Distribution of Chimpanzee Psychopathy Measure Scores}

The mean score on the CPM was 68.17 (SD = 11.06), and CPM scores ranged from 47.96 to 90.72 . CPM scores exhibited minimal skewness $(-.02)$ and were slightly platykurtotic (kurtosis $=-.65)$. There were no unambiguous indications of bimodality in the distribution, although the highest scoring chimpanzee in the sample (a female) scored approximately 6 points higher than the next highest scorer.

\section{Sex and Age Differences}

Males (72.98) scored higher than females (65.87) on the CPM. This difference was marginally significant: $\mathrm{t}(32)=1.81, p<.08$. The effect size of this difference, as measured by Cohen's $d$, was .66, which is medium to large in magnitude (Cohen, 1988). Because the correlations between the CPM and both the personality and observational data were very similar in males and females, only the combined correlational analyses are presented in the remainder of this article. The correlation between the CPM and age was non-significant $(r=-.24)$. 
Table 2. Correlations Between CPM and Primary Ethogram Variables

\begin{tabular}{|c|c|c|c|c|}
\hline \multirow{2}{*}{$\frac{\text { Type of behavior }}{\text { Agonistic behavior }}$} & \multicolumn{2}{|c|}{ Performed } & \multicolumn{2}{|c|}{ Received } \\
\hline & & & & \\
\hline Low-intensity agonism & $.44^{*}$ & $\left(.42^{\star}\right)$ & $.47^{\star \star}$ & $\left(.51^{\star \star}\right)$ \\
\hline High-intensity agonism & .15 & $(.15)$ & -.06 & $(-.06)$ \\
\hline Bluff interaction without vocalization & -.07 & $(-.12)$ & .03 & $(.00)$ \\
\hline Submissive interaction with vocalization & .28 & $(.27)$ & .05 & $(-.11)$ \\
\hline Submissive interaction without vocalization & .06 & $(.10)$ & -.03 & $(-.24)$ \\
\hline Side-directed behavior & .07 & $(.18)$ & -.14 & $(-.27)$ \\
\hline Nonspontaneous submissive greeting & .14 & $(.10)$ & -.06 & $(-.26)$ \\
\hline Submissive greeting & -.12 & $(-.10)$ & -.02 & $(-.22)$ \\
\hline Hooting & .19 & $(.014)$ & -.06 & $(-.24)$ \\
\hline Noise making & .16 & $(.04)$ & -- & \\
\hline Silent bluff display & $.35^{\star}$ & $(.33)$ & -- & \\
\hline Vocal bluff display & -.08 & $(-.22)$ & -- & \\
\hline \multicolumn{5}{|l|}{ Social behavior } \\
\hline Body contact & .02 & $(.21)$ & $-.30 \dagger$ & $(-.21)$ \\
\hline Within arm's reach & $.38^{*}$ & $\left(.37^{\star}\right)$ & $-.31 \dagger$ & $\left(-.35^{\star}\right)$ \\
\hline Play wrestling and tickling & $.40^{\star}$ & $\left(.59^{\star \star \star}\right)$ & .25 & $\left(.45^{\star \star}\right)$ \\
\hline Play chasing & $.37^{\star}$ & $\left(.52^{\star \star}\right)$ & .27 & $\left(.46^{\star \star}\right)$ \\
\hline Hold out hand & .11 & $(.24)$ & -.08 & $(.03)$ \\
\hline \multicolumn{5}{|l|}{ Intensive contacts } \\
\hline Grooming & -.06 & $(-.31) \dagger$ & -.10 & $(-.20)$ \\
\hline Mutual grooming & -.10 & $\left(-.38^{\star}\right)$ & -.13 & $(-.26)$ \\
\hline Unsuccessful groom initiation & .16 & $(.21)$ & .00 & $(-.13)$ \\
\hline Suckling & .24 & $\left(.35^{\star}\right)$ & $-.29 \dagger$ & $(-.34) \dagger$ \\
\hline Kiss or soft gnaw & $.30 \dagger$ & $(.29) \dagger$ & .02 & $(-.02)$ \\
\hline Erotic touch & .17 & $(.12)$ & .10 & $(.11)$ \\
\hline Embrace & -.04 & $(-.06)$ & -.01 & $(-.03)$ \\
\hline Mount-embrace, walk, or carry & -.10 & $(.11)$ & -.01 & $(.08)$ \\
\hline Touch, patting, other gentle hand contact & .17 & $(.31) \dagger$ & .10 & $(.21)$ \\
\hline \multicolumn{5}{|l|}{ Sexual interaction } \\
\hline Genital inspection & .11 & $(.17)$ & $-.30 \dagger$ & $(-.29)$ \\
\hline Mount without intromission & $.37^{*}$ & $\left(.42^{\star}\right)$ & .02 & $(.14)$ \\
\hline Mount with intromission & .16 & $(.23)$ & -.09 & $(-.07)$ \\
\hline Sexual invitation by female & .12 & $(.14)$ & .10 & $(.18)$ \\
\hline Sexual invitation by male & .11 & $(.10)$ & -.23 & $(-.30)$ \\
\hline \multicolumn{5}{|l|}{ Vocalizations } \\
\hline Whimper or yelp & -.08 & $(-.01)$ & .24 & $(.25)$ \\
\hline \multicolumn{5}{|l|}{ Abnormal behavior } \\
\hline Repetitive movement & $-.45^{\star \star}$ & $(-.39 *)$ & -- & \\
\hline \multicolumn{5}{|l|}{ Other behaviors } \\
\hline Gentle teasing & $.34^{*}$ & $\left(.43^{\star}\right)$ & $-.46^{\star \star}$ & $\left(-.44^{\star}\right)$ \\
\hline Temper tantrums & $.32 \dagger$ & $\left(.37^{\star}\right)$ & -.22 & $(-.15)$ \\
\hline \multicolumn{5}{|l|}{ Complex behaviors } \\
\hline Aggravation & .25 & $(.25)$ & .06 & $(.03)$ \\
\hline Babysitting & $.40^{\star}$ & $(.40)$ & .01 & $(.09)$ \\
\hline Daring & $.35^{\star}$ & $\left(.38^{\star}\right)$ & -.05 & $(-.12)$ \\
\hline Detachment & $-.45^{\star \star}$ & $\left(.41^{*}\right)$ & -- & \\
\hline Generosity & $-.38^{*}$ & $(.33)$ & .24 & $(.33)$ \\
\hline Greediness & .01 & $(-.03)$ & -.07 & $(.06)$ \\
\hline Isolation & $-.31 \dagger$ & $(-.28)$ & -- & \\
\hline Rejection & -.21 & $(-.35)^{\star}$ & -.03 & $(.04)$ \\
\hline
\end{tabular}




\section{Correlations With Personality Traits}

The CPM correlated negatively $(r=-.42, p<.05)$ with the non-overlapping Agreeableness scale and positively $(r=.60, p<.01)$ with the non-overlapping Extraversion scale. The correlation between the CPM and the non-overlapping Neuroticism scale was positive but non-significant $(r=.28)$.

\section{Correlations With Observational Data}

The correlations between the CPM and the primary ethogram variables are displayed in Table 2. As can be seen in this table, the CPM correlated positively and significantly with a number of performed behaviors, including low-intensity agonism, silent bluff displays, within arm's reach, both types of play behavior, mounting without intromission, gentle teasing, babysitting, and daring actions. In addition, the correlations between the CPM and kiss or soft gnaw and temper tantrums were marginally significant. Contrary to prediction, the CPM was uncorrelated with greediness. The CPM correlated negatively and significantly with the performed behaviors of repetitive movement, detachment, and generosity. ${ }^{3}$ The negative correlation between the CPM and isolation was marginally significant. The correlations between the CPM and received behaviors were less numerous. The CPM correlated positively and significantly with received low-intensity agonism and negatively and significantly with received gentle teasing. The negative correlations between the CPM and received body contact, within arm's reach, suckling, and genital inspection were marginally significant.

Table 3. Correlations Between CPM and Ad Libitum Ethogram Variables

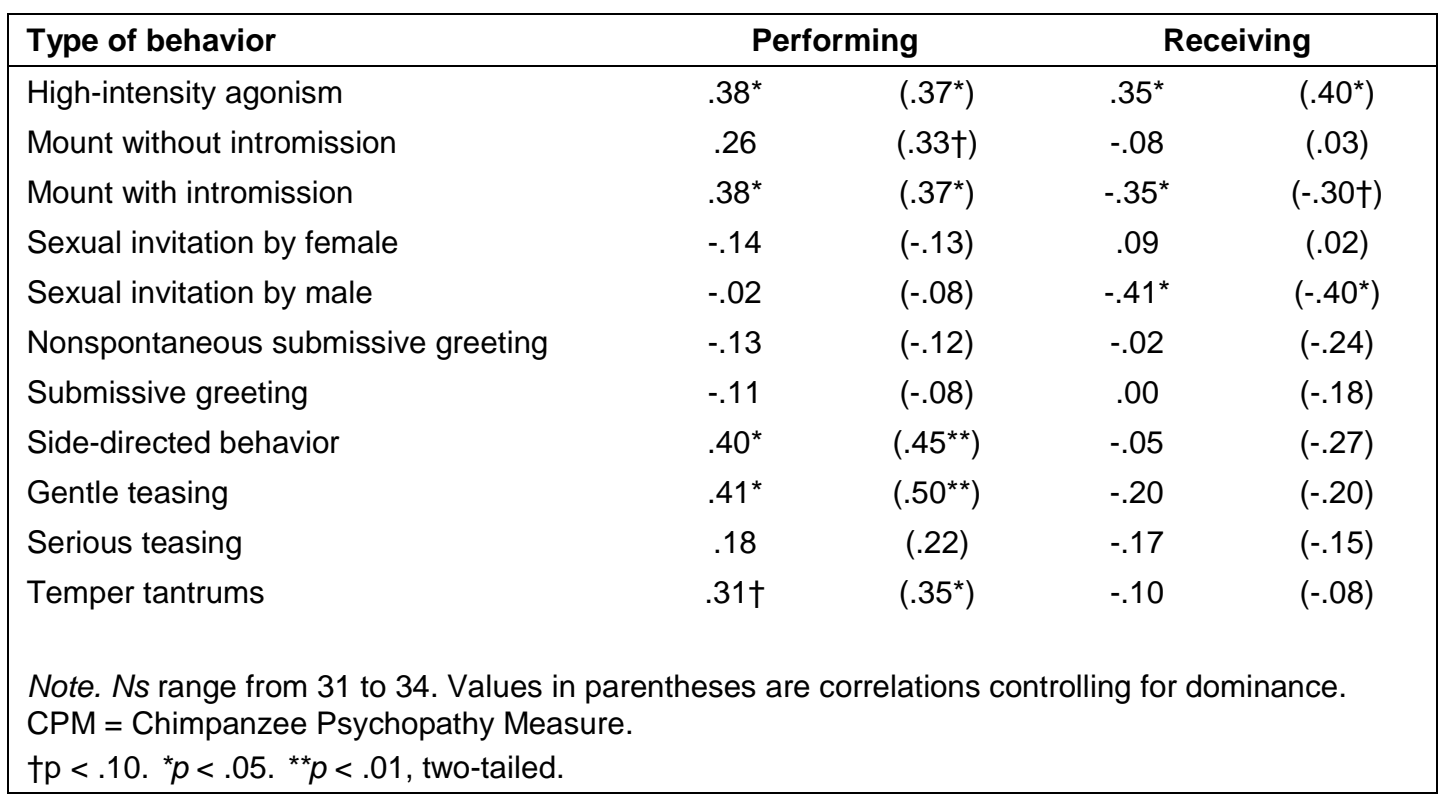

The correlations between the CPM and the ad libitum ethogram data are displayed in Table 3. The CPM correlated positively and significantly with the performed behaviors of high-intensity agonism, mount with intromission, side-directed behavior, and gentle teasing. The correlation with temper tantrums was positive and marginally significant. The CPM correlated positively and significantly with received highintensity agonism and negatively and significantly with mount with intromission and sexual invitation by male. To exclude the possibility that the correlations between the CPM and the primary and ad libitum ethogram variables were attributable to criterion contamination, we recomputed these correlations by 
excluding the 2 individuals who had completed both the CPM and ethogram ratings from the computation of the CPM score. These analyses were very similar to those reported here. ${ }^{4}$

\section{Incremental Validity of the Chimpanzee Psychopathy Measure Above and Beyond Dominance}

To examine the incremental validity of the CPM above and beyond dominance, we next computed partial correlations between the CPM and the primary and ad libitum ethogram variables controlling for dominance (as assessed by the dominance item within the CPM). When conducting these analyses, the dominance item was omitted from the total CPM score. ${ }^{5}$ These partial correlations are displayed in parentheses in Tables 2 and 3. Relatively few correlations changed dramatically in magnitude, although the negative correlations between the CPM and performed grooming and mutual grooming became marginally significant and significant, respectively. We also recomputed all of the partial correlations using a composite variable formed by summing the dominance item from the CPM and the (reversed) subordinate item from the Extraversion scale. The results of these analyses were very similar to those found using the dominance item alone. ${ }^{6}$

\section{Discussion}

The results reported here provide preliminary evidence for the reliability and construct validity of the CPM and, by extension, for the relevance of the psychopathy construct to chimpanzees. The CPM was reliable across raters and internally consistent. As would be expected from the literature on sex differences in psychopathy in humans (Widom, 1984 ), males received higher CPM scores than females, although this difference was only marginally significant. Nevertheless, because raters were instructed to rate each chimpanzee compared with others of its own sex, this analysis provides a conservative test of sex differences on the CPM. The CPM was significantly correlated with ratings of Big Five Agreeableness (negatively) and Extraversion (positively), corroborating most findings in the human psychopathy literature (Hart \& Hare, 1994; but see Harpur et al., 1994, for data calling into question the relation between psychopathy and extraversion).

The CPM correlated positively and in most cases significantly with ethogram measures of agonism, sexual activity, daring behaviors, gentle teasing, silent bluff displays, and temper tantrums. These findings are consistent with descriptions of human psychopaths as aggressive, sexually promiscuous, sensation seeking, interpersonally provocative, and short tempered (Cleckley, 194111982; Hare, 1991). In addition, the CPM correlated negatively and significantly with ethogram measures of generosity and repetitive movement. The negative correlation with generosity is consistent with descriptions of human psychopaths as self-centered and concerned primarily with satisfying their own desires (Hare, 1991). Because repetitive movements include solitary rocking, clasping of hands, and other actions that appear to be associated with anxiety and emotional disturbance, the negative correlation of the CPM with this variable is consistent with the contention that psychopaths are relatively free of nervousness and compulsive behaviors (Cleckley, 1941/1982). The positive correlation between the CPM and side-directed behavior in the ad libitum data may reflect the close association of side-directed behavior with agonism (de Waal, 1998; de Waal \& van Hooff, 1981).

The relations between the CPM and ethogram ratings extend the findings of other recent research (e.g., King \& Figueredo, 1997) by providing data on the behavioral correlates of a measure of chimpanzee personality. These correlates argue against the hypothesis that interrater agreement on the CPM is attributable to raters' reliance on obvious but erroneous external cues (e.g., body size), because these correlates accord largely with clinical descriptions of human psychopathy (e.g., Cleckley, 1941/1982). Moreover, the fact that gentle teasing and temper tantrums emerged as significant and marginally significant correlates, respectively, of the CPM in both the primary and ad libitum ethogram data renders it 
unlikely that our principal findings are attributable to Type I error. The CPM also demonstrated incremental validity above and beyond measures of dominance in predicting ethogram ratings, suggesting that the psychopathy construct in chimpanzees encompasses more than status in the social hierarchy. Nevertheless, because dominance was measured by only one item (and in subsidiary analyses, two items), it will be important in future research to assess dominance in a multidimensional fashion (e.g., by aggregating across multiple behavioral indexes).

Several of our findings ran counter to prediction. The CPM was not associated with greediness, despite the fact that self-centeredness and opportunism have traditionally been considered core features of psychopathy in humans (Cleckley, 194111982; Hare, 1991). Because the behavior of greediness was performed on only four occasions (by 4 different animals), however, it will be necessary to replicate this negative finding in samples exhibiting a higher frequency of this behavior. In addition, several ethogram correlates of the CPM, particularly babysitting, were not anticipated. It should be noted, however, that babysitting was observed in only 2 animals (both female), 1 of whom had a history of snatching babies from other mothers. Thus, the positive correlation between the CPM and babysitting may in fact provide support for the construct validity of the CPM, although additional research will be necessary to substantiate this possibility.

Our results do not imply that we have identified the full syndrome of psychopathy in chimpanzees. Because chimpanzees' sense of morality is unlikely to be as complex or differentiated as that of humans, the construct of psychopathy may possess a somewhat different meaning in chimpanzees and humans. Moreover, because the extent to which chimpanzees can model the mental states of other animals requires further investigation (de Waal, 1996; Povinelli, Nelson, \& Boysen, 1992), the relevance of the construct of empathy to chimpanzees remains unclear. Nevertheless, our findings provide initial support for the contention that certain features of human psychopathy, such as risk taking and absence of generosity, may be applicable to great apes.

Several limitations of the present findings should be noted. First, because the items on the Big Five measures overlapped substantially with those on the CPM, there were only two items each on the nonoverlapping Agreeableness and Neuroticism indexes. Although the two items within each of these measures were highly correlated, these measures were limited in coverage of their corresponding Big Five dimensions. In addition, an insufficient number of items was available to assess the Big Five dimensions of Conscientiousness and Openness to Experience. Because Conscientiousness tends to be negatively correlated with psychopathy in humans (Hart \& Hare, 1994 ), inclusion of a measure of Conscientiousness in future research on chimpanzees could help to provide additional construct validation for the CPM.

Second, because our sample size was relatively small, a number of CPM correlates (e.g., aggravation, mount with intromission in the ad libitum data) may have failed to reach statistical significance because of low statistical power. Further investigation of the behavioral correlates of the CPM in larger samples is clearly necessary. Our small sample size also precluded us from drawing conclusions regarding the factor structure of the CPM. Although exploratory factor analyses of the CPM in this sample (not reported here) did not yield psychologically interpretable solutions, sample sizes of approximately 100 are generally a minimum for obtaining a replicable factor structure, and even sample sizes of 200 often yield unstable results (Barrett \& Kline, 1981; Cliff, 1970). Factor analyses of the most extensively validated measure of psychopathy in humans, Hare's (1991) Psychopathy Checklist-Revised, have typically revealed a twofactor structure (Harpur et al., 1989), with the first factor associated primarily with the core personality features of psychopathy and the second factor associated primarily with overt aggression. If a two-factor structure were obtained for the CPM in larger samples, this finding would provide additional support for the construct validity (specifically, factorial validity; see Guilford, 1946) of this measure. 
Third and finally, although the ethogram data offer support for the validity for the CPM, this support should be regarded as preliminary. Because the ethogram data and CPM ratings were both derived from behavioral observations of the chimpanzees, it could be argued that the relations between the CPM and ethogram ratings reflect temporal stability as much as validity. It should be noted, however, that several ethogram correlates of the CPM (e.g., sexual behaviors, silent bluff displays, repetitive movements) did not overlap in overt content with any of the CPM items, suggesting that the CPM may assess a relatively broad disposition toward psychopathic personality traits.

Nevertheless, a broader program of research incorporating indexes such as biological measures and laboratory tasks will be required to provide further evidence for the construct validity of the CPM. For example, because low levels of serotonin are associated with aggression, poor impulse control, and other psychopathic traits in both humans and nonhuman primates (Higley \& Linnoila, 1997), a negative correlation between the CPM and serotonin metabolites would be anticipated. In addition, because deficits in passive-avoidance learning (the capacity to withhold responses that lead to punishment) have been found to distinguish psychopaths from non-psychopaths in human studies (e.g., Lykken, 1957; Newman \& Kosson, 1986), administration of passive-avoidance (e.g., go-no go) tasks to chimpanzees in conjunction with the CPM could provide additional construct validation for this measure. Such investigations would help to embed the CPM within a nomological network (Cronbach \& Meehl, 1955) of predictions and provide a richer theoretical context for examining the applicability of the psychopathy construct to our closest animal relatives.

\section{References}

Altmann, J. (1974). Observational study of behavior: Sampling methods. Behaviour; 49, 227-265.

Barrett, P. T., \& Kline, P. (1981). The observation to variable ratio in factor analysis. Personality Study and Group Behavior, 1, 23-33.

Bolig, R., Price, C. S., O'Neill, P. L., \& Suomi, S. J. (1992). Subjective assessment of reactivity level and personality traits of rhesus monkeys. International Journal of Primatology, 13, 287-306.

Buirski, P., \& Plutchik, R. (1991). Measurement of deviant behavior in a Gombe chimpanzee: Relation to later behavior. Primates, 32,207-211.

Byrne, R., \& Whiten, A. ( 1988). Machiavellian intelligence: Social expertise and the evolution of intellect in monkeys, apes, and humans. Oxford, England: Clarendon Press.

Caine, N., Earle, H., \& Reite, M. (1983). Personality traits of adolescent pig-tailed monkeys (Macaca nemesterina): An analysis of social rank and early separation. American Journal of Primatology, 4, 253-260.

Chamove, A., Eysenck, H. J., \& Harlow, H. (1972). Personality in monkeys: Factor analyses of rhesus social behavior. Quarterly Journal of Experimental Psychology, 24, 496-504.

Clarke, A. S., \& Boinski, S. (1995). Temperament in nonhuman primates. American Journal of Primatology, 37, 103-125.

Cleckley, H. (1982). The mask of sanity. St. Louis, MO: Mosby. (Original work published 1941)

Cliff, N. (1970). The relation between sample and population characteristic vectors. Psychometrika, 35, 163-178. 
Cohen, J. (1988). Statistical power analysis for the behavioral sciences. Hillsdale, NJ: Erlbaum.

Costa, P. T., \& McCrae, R. R. (1992). Four ways the five factors are basic. Personality and Individual Differences, 13, 653-665.

Cronbach, L. J., \& Meehl, P. E. (1955). Construct validity in psychological tests. Psychological Bulletin, 52, 281-302.

de Waal, F. B. M. (1991). The chimpanzee's sense of social regularity and its relation to the human sense of justice. American Behavioral Scientist, 34, 335-349.

de Waal, F. B. M. (1992). Intentional deception in primates. Evolutionary Anthropology, 1, 86-92.

de Waal, F. B. M. (1996). Good natured: The origins of right and wrong in humans and other animals. Cambridge, MA: Harvard University Press.

de Waal, F. B. M. (1998). Chimpanzee politics: Power and sex among apes (Rev. ed.). Baltimore: Johns Hopkins University Press.

de Waal, F. B. M., \& Hoekstra, J. (1980). Contexts and predictability of aggression in chimpanzees. Animal Behaviour, 28, 929-937.

de Waal, F. B. M., \& van Hooff, J. A. (1981). Side-directed communication and agonistic interactions in chimpanzees. Behaviour, 77, 164-198.

Draper, T. W. (1995). Canine analogs of human personality factors. Journal of General Psychology, 122, 241-255.

Epstein, S. (1979). The stability of behavior: I. On predicting more of the people more of the time. Journal of Personality and Social Psychology, 37, 1097-1126.

Figueredo, A. J ., Cox, R. L., \& Rhine, R. J. (1995). A generalizability analysis of subjective personality assessments in the stumptail macaque and the zebra finch. Multivariate Behavioral Research, 30, 167-197.

Garda-Sevilla, L. (1984). Extraversion and neuroticism in rats. Personality and Individual Differences, 5, 511-532.

Gershon, J. (1998). The relations among personality, hierarchy, and nonverbal behavior in chimpanzees. Unpublished master's thesis, Emory University, Atlanta, GA.

Gold, K. C., \& Maple, T. L. (1994). Personality assessment in the gorilla and its utility as a measurement tool. Zoo Biology, 13, 509-522.

Goodall, J. (1990). Through a window: My thirty years with the chimpanzees of Gombe. Boston: Houghton Mifflin.

Goodall, J. (1991). Unusual violence in the overthrow of an alpha male chimpanzee at Gombe. In T. Nishida (Ed.), Topics in primatology: Human origins (Vol. 1, pp. 131-142). Tokyo: University of Tokyo Press.

Gosling, S. D. (1998a). From mice to men: What can animal research tell us about human personality? Manuscript submitted for publication. ' 
Gosling, S. D. (1998b). Personality dimensions in spotted hyenas (Crocuta crocuta). Journal of Comparative Psychology, 112, 107-118.

Gosling, S. D., \& John, O. P. (1999). Personality dimensions in non-human animals: A cross-species review. Current Directions in Psychological Science, 8, 69-75.

Guilford, J. P. (1946). New standards for test validation. Educational and Psychological Measurement, 6 , 427-438.

Hare, R. D. (1991). The Psychopathy Checklist-Revised. Toronto, Ontario, Canada: Multi-Health Systems.

Harkness, A. R., Tellegen, A., \& Waller, N. (1995). Differential convergence of self-report and informant data for Multidimensional Personality Questionnaire traits: Implications for the construct of negative emotionality. Journal of Personality Assessment, 64, 185-204.

Harpur, T. J., Hare, R. D., \& Hakstian, A. R. (1989). Two-factor conceptualization of psychopathy: Construct validity and assessment implications. Psychological Assessment, 1, 6-17.

Harpur, T. J., Hart, S.D., \& Hare, R. D. (1994). Personality of the psychopath. In P. T. Costa \& T. A. Widiger (Eds.), Personality disorders and the five-factor model of personality (pp. 149-173). Washington, DC: American Psychological Association.

Harris, G. T., Rice, M. E., \& Quinsey, V. L. (1994). Psychopathy as a taxon: Evidence that psychopaths are a discrete class. Journal of Consulting and Clinical Psychology, 62,387-397.

Hart, S. D., \& Hare, R. D. (1994). Psychopathy and the Big 5: Correlations between observers' ratings of normal and pathological personality. Journal of Personality Disorders, 8, 32-40.

Hauser, M.D. (1997). Minding the behaviour of deception. In A. Whiten \& R. W. Byrne (Eds.), Machiavellian intelligence II: Extensions and evaluations (pp. 112-143). Cambridge, England: Cambridge University Press.

Higley, J.D., \& Linnoila, M. (1997). Low central nervous system serotonergic activity is trait-like and correlates with impulsive behavior: A nonhuman primate model investigating genetic and environmental influences on neurotransmission. In D. M. Stoff \& J. Mann (Eds.), The neurobiology of suicide: From the bench to the clinic (pp. 39-56). New York: New York Academy of Sciences.

Kagan, J., Reznick, J. S., \& Snidman, N. (1987). The physiology and psychology of behavioral inhibition in young children. Child Development, 58, 1459-1473.

Kazdin, A. E. (1983). Psychiatric diagnosis, dimensions of dysfunction, and behavior therapy. Behavior Therapy, 14,73-99.

Kenrick, D. T., \& Funder, D. C. ( 1988). Profiting from controversy: Lessons from the person-situation debate. American Psychologist, 43, 23-34.

King, J. E., \& Figueredo, A. J. (1997). The five-factor model plus dominance in chimpanzee personality. Journal of Research in Personality, 31, 257-271. 
Lilienfeld, S. 0. (1992). The association between antisocial personality and somatization disorders: A review and integration of theoretical models. Clinical Psychology Review, 12, 641-662.

Lilienfeld, S. 0. (1994). Conceptual problems in the assessment of psychopathy. Clinical Psychology Review, 14, 17-38.

Lykken, D. T. (1957). A study of anxiety in the sociopathic personality. Journal of Abnormal and Social Psychology, 55, 6-10.

Lykken, D. T. (1995). The antisocial personalities. Hillsdale, NJ: Erlbaum.

McCord, W., \& McCord, J. (1964). The psychopath: An essay on the criminal mind. Princeton, NJ: Van Nostrand.

Mealey, L. (1995). Primary sociopathy (psychopathy) is a type, secondary is not. Behavioral and Brain Sciences, 18, 579-599.

Meehl, P. E., \& Golden, R. R. (1982). Taxometric methods. In P. C. Kendall \& J. N. Butcher (Eds.), Handbook of research methods in clinical psychology (pp. 127-181). New York: Guilford Press.

Menzel, E. W. (1974). A group of young chimpanzees in a one-acre field: Leadership and communication. In A. Schrier \& F. Stollnitz (Eds.), Behavior in nonhuman primates (pp. 83-153). New York: Academic Press.

Newman, J.P., \& Kosson, D. S. (1986). Passive avoidance learning in psychopathic and nonpsychopathic offenders. Journal of Abnormal Psychology, 95, 252-256.

Nishida, T., \& Hosaka, K. (1996). Coalition strategies among adult male chimpanzees of the Mahale Mountains, Tanzania. In W. C. McGrew, L. F. Marchant, \& T. Nishida (Eds.), Great ape societies (pp. 114-134). New York: Cambridge University Press.

Povinelli, D. J., Nelson, K. E., \& Boysen, S. T. (1992). Comprehension of social role reversal by chimpanzees: Evidence of empathy? Animal Behaviour, 43, 633-640.

Sapolsky, R. M. (1990, January). Stress in the wild. Scientific American, 116-123.

Savage-Rumbaugh, S., \& McDonald, K. (1988). Deception and social manipulation in symbol-using apes. In R. Byrne \& A. Whiten (Eds.), Machiavellian intelligence: Social expertise and the evolution of intellect in monkeys, apes, and humans (pp. 224-237). Oxford, England: Clarendon Press.

Sechrest, L. (1963). Incremental validity: A recommendation. Educational and Psychological Measurement, 23, 153-158.

Solomon, R. L. (1960). Letter quoted by 0. H. Mowrer. Learning theory and the symbolic processes (pp. 399-404). New York: Wiley.

Stevenson-Hinde, J., Stillwell-Barnes, R., \& Zunz, M. (1980). Subjective assessment of rhesus monkeys over four successive years. Primates, 21, 66-82.

Stevenson-Hinde, J., \& Zunz, M. (1978). Subjective assessment of individual rhesus monkeys. Primates, 19,473-482. 
Suomi, S. J. (1991). Uptight and laid-back monkeys: Individual differences in response to social challenges. In S. E. Brauth, W. S. Hall, \& R. J. Dooling (Eds.), Plasticity of development (pp. 2756). Cambridge, MA: MIT Press.

van Hooff, J. A. (1973). A structural analysis of the social behavior of a semi-captive group of chimpanzees. In M. von Cranach \& I. Vine (Eds.), Social communication and movement: Studies of interaction and expression in man and chimpanzee (pp. 75-162). London: Academic Press.

Widom, C. S. (1984). Sex roles, criminality, and psychopathology. In C. S. Widom (Ed.), Sex roles and psychopathology (pp. 183-217). New York: Plenum.

Woodruff, G., \& Premack, D. (1979). Intentional communication in the chimpanzee: The development of deception. Cognition, 7, 333-362.

Wrangham, R., \& Peterson, D. (1996). Demonic males: Apes and the origins of human violence. Boston: Houghton Mifflin.

Zuckerman, M. (1984). Sensation seeking: A comparative approach to a human trait. Behavioral and Brain Sciences, 7, 413-471.

${ }^{1}$ Even if psychopathy is taxonic, this would not necessarily preclude detecting correlations between psychopathy and other variables, provided that the base rate of the psychopathy taxon is sufficiently high (see Meehl \& Golden, 1982).

2 As noted in the following paragraph, two of the three non-overlapping personality scales also consisted of two items. Nevertheless, both Conscientiousness items (impulsive, reversed, and delays gratification, reversed) overlapped with the CPM.

3 To exclude the possibility that the significant negative correlation between the CPM and generosity was attributable to the inclusion of the item "generous" in the CPM, this correlation was recomputed after excluding this item. This correlation remained virtually unchanged $(r=-.38, p<.05)$.

${ }^{4}$ We also recomputed the correlations between the CPM and ethogram behaviors after controlling for age. These correlations were very similar to those reported here. . .

${ }^{5}$ The correlations between CPM scores and the Big Five dimensions remained quite similar after controlling for dominance, although the partial correlation between the CPM and Neuroticism attained significance $(r=.36, p<$ $.05)$.

${ }^{6}$ We also examined the incremental validity of the CPM above and beyond Extraversion to exclude the hypothesis that the behavioral correlates of the CPM were attributable to a general dimension comprising activity level, liveliness, and related traits. The principal ethogram correlates of the CPM remained similar after controlling for Extraversion, although several became non-significant. Notably, the correlations between the CPM and lowintensity agonism in the primary ethogram $(r=.34, p<.06)$ and high-intensity agonism in the ad libitum ethogram $(r=.38, p<.05)$ remained moderate in magnitude. 


\section{Appendix}

List of Ethogram Behaviors

\section{Agonistic Behavior}

Low-intensity agonism: animal engages in aggressive behaviors (e.g., bite, brusque rush, tug/grab) in a nonserious manner.

High-intensity agonism: animal engages in aggressive behaviors (see above) in a serious manner (i.e., a serious physical hit, sustained aggression, or injurious behavior).

Bluff interaction without vocalization: animal exhibits bluff displays but without low- or high-intensity agonism or vocalization.

Submissive interaction with vocalization: same as above, except must be accompanied by vocalization (e.g., bared-teeth help or scream).

Submissive interaction without vocalization: animal exhibits submissive behavior (e.g., avoidance, flight, withdrawal, parry, or flinching). Must be no vocalization.

Side-directed behavior: a nonagonistic interaction occurs between two animals during an agonistic exchange with another animal.

Nonspontaneous submissive greeting

Submissive greeting: animal makes at least 2 pant-grunts.

Hooting

Noise making

Silent bluff display

Vocal bluff display

\section{Social Behavior}

Body contact: includes huddle, contact-sit, social rocking, but not play.

Within arm's reach

Play wrestling and tickling

Play chasing

Hold out hand

\section{Intensive Contacts}

\section{Grooming}

Mutual grooming

Unsuccessful groom initiation: animal is rejected by partner by leaving, turning away, or hand gesture; or grooming episode lasts less than $5 \mathrm{~s}$.

\section{Suckling}

Kiss or soft gnaw

Erotic touch: includes tongue kiss, masturbation of others, and finger in vagina not followed by sniffing, contact of mouth or hand to penis; must be without mounting or mating.

\section{Embrace}


Mount-embrace, walk, or carry

Touch, patting, other gentle hand contact

\section{Sexual Interaction}

Genital inspection: sniffing of genitals; finger in vagina if sniffing follows.

Mount without intromission: for mount by female or without pelvic thrusts.

Mount with intromission

Sexual invitation by female: crouch present.

Sexual invitation by male: concave back, penile erection.

\section{Vocalizations}

Whimper or yelp

\section{Abnormal Behavior}

Repetitive movement: includes head shaking (repetitive), solitary or social rocking, pirouette, clap hands, repetitive swinging or repetitive movements of hands or mouth.

\section{Other Behaviors}

Gentle teasing: mild hitting or slapping by juveniles to adults, including sexual harassment; involves no action by the recipient.

Temper tantrums: angry outbursts accompanied by spasmodic movements; involves no action by the recipient.

\section{Complex Behaviors}

Aggravation: animal continues to engage in a behavior when another animal is clearly uninterested in continuing.

Babysitting: animal takes care of a juvenile while the mother is not watching.

Daring: animal engages in acts that could elicit aggression from a higher ranking animal.

Detachment: animal remains alone while most members of the group are engaged in another activity.

Generosity: individual willingly shares food or other desired object.

Greediness: individual does not share food or other desired object.

Isolation: awake animal remains alone for extended period of time without attempting interaction with others.

Rejection: individual approaches another animal in the group in an effort to engage in play, grooming, or other social interaction, and other animal shows no interest. 